\title{
O eu no nós: reconhecimento como força motriz de grupos
}

\section{Resumo}

Neste texto, analisam-se o conceito de grupo e suas manifestações, buscando contrapor às perspectivas categoriais da psicanálise e da teoria sociológica, consideradas incompletas em razão de estilizações unilaterais que impedem uma conexão conceitual básica entre as duas disciplinas, uma terminologia que, de partida, seja neutra frente às alternativas positiva e negativa de inserção do eu no grupo. Para tanto, o grupo, independentemente de seu tamanho e tipo, inicialmente deve ser compreendido como um mecanismo social fundado na necessidade ou no interesse psíquico do indivíduo, porque o auxilia na estabilidade e ampliação pessoais. $\mathrm{O}$ artigo descreve, em linhas gerais, o arcabouço categorial unificado, recorrendo ao conceito do reconhecimento. Num primeiro passo, apresenta-se brevemente a premissa de que a dependência individual de experiências de reconhecimento social explica por que o sujeito individualmente aspira a ser membro em diferentes modelos de agrupamentos sociais. Num segundo passo, tenta-se corrigir a imagem idealizada de grupo anteriormente introduzida, ao tematizar as tendências regressivas que frequentemente codeterminam a vivência no grupo. Por fim, segue-se a ideia de retirar gradativamente aquelas idealizações que estavam na base da premissa inicial de uma diluição harmônica do eu no nós do grupo.

Palavras-chave: Teoria do reconhecimento. Psicologia social. Agrupamentos sociais. Individualização. Socialização.

पLivre-docente em Filosofia. Diretor do Instituto de Pesquisa Social e catedrático de Filosofia Social na Universidade de Frankfurt am Main (Alemanha).E-mail: honneth@em.uni-frankfurt.de 
Sociologias, Porto Alegre, ano 15, no 33, mai./ago. 2013, p. 56-80

\section{The I in we: recognition as a driving force of group formation ${ }^{1}$}

\section{Abstract}

This paper analyzes the concept of group and its manifestations, seeking to contrast the categorial perspectives of both psychoanalysis and sociological theory, which are considered incomplete because of unilateral stylizations that prevent a basic conceptual connection between the two disciplines, with a terminology conceived to be neutral faced with positive and negative alternatives for insertion of the self in the group. To this end, the group, regardless of its size and type, should be initially understood as a social mechanism based on the individual's psychic need or interest, because it helps in his stability and personal development. The article outlines the unified categorial framework resorting to the concept of recognition. In a first step, I briefly present the premise that the individual's dependence on experiences of social recognition explains why the subject individually aspires to membership in different models of social groupings. In a second step, I try to correct the previously introduced idealized image of group, by thematizing the regressive tendencies that often co-determine the experiencing within the group. Finally, I proceed with the idea of progressively withdrawing those idealizations that were based on the initial premise of a harmonic blending of I in we in the group. Keywords: Theory of recognition. Social psychology. Social groupings. Individualization. Socialization.

\footnotetext{
${ }^{1}$ Das Ich im Wir: Anerkennung als Triebkraft von Gruppen, In: Honneth, Axel, Das Ich im Wir: Studien zur Anerkennungstheorie (Frankfurt am Main, Suhrkamp, 2010, p. 261-279). Publicado com autorização da editora Suhrkamp, detentora dos direitos autorais. Tradução do alemão: Emil A. Sobottka.
} 


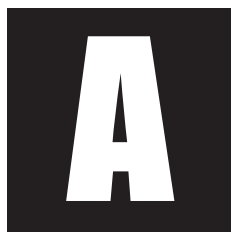

inda que o conceito "grupo" tenha enorme plasticidade e possa ser utilizado para fenômenos sociais muito distintos, cada época histórica extrai da multiplicidade das manifestações alguns traços especialmente marcantes para construir, com eles, sua própria imagem de grupo. Nessas construções, espelham-se medos e esperanças, temores e expectativas, que são impulsionados por vivências típicas de época sobre a união de indivíduos em associações relativamente estáveis e duradouras. Um breve olhar sobre a movimentada história do século 20 já revela quão diferentes têm sido as associações que foram feitas com o surgimento e a disseminação de grupos sociais sob a impressão de determinadas experiências, rapidamente generalizadas. No início, a experiência do grande grupo anônimo e submisso à autoridade captura tanto a atenção social, que o conceito de grupo, de Freud e Canetti até Adorno, está marcado quase totalmente pela imagem da massa regressiva ${ }^{2}$. Mais tarde, depois do final da Segunda Guerra Mundial, frequentemente esta concepção negativa é transferida à categoria da gangue, do pequeno grupo de jovens violentos, em cujo uso popular se espelham os medos da crescente sociedade de bem-estar face aos perdedores que ela própria produziu ${ }^{3}$. Paralelamente às estilizações negativas, no entanto, também faz parte da história dessas imagens sociais sobre o grupo, no século 20, o surgimento de construções positivas, nas quais se refletem esperanças de um efeito benéfico dos agrupamentos sociais. Depois que a psicologia social estadunidense descobriu as funções civilizatórias dos grupos de jogos e de vizinhança (cf. Cooley, 1963), depois que Piaget, em seu estudo ino-

\footnotetext{
${ }^{2}$ Freud (1999); Canetti (1960); Adorno (1972). Sobre o significado do conceito massa na sociologia alemã, cf. Berking (1984).

${ }^{3} \mathrm{O}$ tema das gangues, que remonta ao estudo clássico de Trasher (1927), foi retomado na Alemanha nos anos 1950 sob o conceito dos semi-fortes (die Halbstarken) (Kluth, 1956).
} 
vador sobre o desenvolvimento moral da criança, provou a importância socializadora do grupo de pares (Piaget, 1976, cap. 3), firmaram-se rapidamente expectativas exageradas sobre a existência de grupos sociais primários, nos quais se via uma garantia natural de relações sociais livres de conflito. E hoje, em consequência da popularização do comunitarismo, a figura da comunidade cultural tomou o lugar desse ideal de grupo, em cujo ambiente impregnado de valores, o indivíduo deve poder desenvolver uma personalidade forte, que ele não pode atingir nas meras relações jurídicas da sociedade. ${ }^{4}$

Por mais diferentes que pudessem ser essas construções de grupo típicas de cada época, elas se assemelham muito na tendência formal de sempre selecionar apenas um dos possíveis atributos de agrupamentos sociais e estilizá-lo como a característica que tudo define. Nas concepções negativas, os traços grupais regressivos, ameaçadores do eu, foram generalizados a tal ponto que, da multiplicidade de suas manifestações sociais, restou tão somente a tediosa massa; enquanto nas concepções positivas, os elementos civilizadores, fortalecedores do eu, foram idealizados a tal ponto que, imperceptivelmente, os riscos da perda de autonomia tiveram que passar despercebidos. Na forma dessas perspectivas unilaterais, tais teorias frequentemente influenciaram a consciência cotidiana comum, ao contribuírem para a formação de mitologias sociais, que logo depois estariam refletidas na literatura ou nos meios de comunicação. As imagens sobre o efeito dos grupos sociais que aqui prevaleceram eram, de certo modo, um aproveitamento seletivo de teorias científicas que, por meio de uma abstração metodológica, se haviam concentrado em determinados traços dos grupos sociais. Evidentemente que, desse processo, também

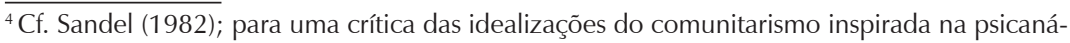
lise, cf. Fink-Eitel (1993). 
resultou regularmente o risco de um circuito fechado, o qual consistia em que as próprias mitologias cotidianas exerciam influência sobre as mesmas pesquisas científicas de cuja generalização popular elas em boa medida retiravam sua matéria prima. Então, paradoxalmente, os pesquisadores tornaram-se vítimas de mitologias sociais para cuja produção eles involuntariamente haviam contribuído, quando, em uma redução consciente, eles se ocuparam de tão somente um aspecto do fenômeno social. Ao longo de todo o século 20, reiteradamente ocorreram tais efeitos retroativos, incontrolados, de imagens sociais popularizadas sobre a formação da teoria. Até hoje prevalece a tendência de deixar sobressaírem-se do grupo social ou apenas os traços regressivos, ou aqueles que fomentam a autonomia, sem levar em consideração seu enraizamento no mesmo mecanismo. Assim, ocorre que, na psicanálise, lamentavelmente, ainda prevalece uma imagem predominantemente negativa do grupo, cuja existência, em seguimento a Freud, é explicada geralmente pelos impulsos de uma compensação da fraqueza do eu. Consequentemente, as atenções se voltam aqui, sobretudo, aos processos regressivos através dos quais, na vida em grupos, camadas primitivas da psique individual são reativadas. Na sociologia e na teoria política, ao contrário, prevalece atualmente uma imagem predominantemente positiva do grupo, totalmente impregnada pela manifestação da comunidade cultural, ou seja, pelo pequeno ou grande grupo integrado por linguagem, tradições e valores. Por conseguinte, as atenções se voltam, aqui, unilateralmente, a processos pelos quais, na forma do desvio face aos sistemas predominantes de valor, são geradas identidades coletivas que devem dar ao indivíduo segurança e integridade psíquica.

As supressões recíprocas não têm como consequência apenas o fato que as duas orientações na pesquisa não conseguem mais reconhecer o quanto sua própria área de investigação também é influenciada pela ou- 
tra tendência. Tal como a psicanálise não consegue admitir que a imersão no grupo social pode beneficiar as forças do eu do indivíduo, também na pesquisa sociológica sobre grupos falta a consciência dos riscos que podem ameaçar o indivíduo pela reativação inconsciente de antigas relações com objetos. Mais grave, contudo, é que as estilizações unilaterais parecem impedir radicalmente uma conexão conceitual básica entre as duas disciplinas. As motivações que cada uma aponta como responsáveis pela entrada no grupo diferem tanto, que surge a impressão de se tratarem de dois fenômenos sociais totalmente diversos. Só é possível superar atualmente este risco, tomando como ponto de partida categorial para a explicação de grupos sociais uma terminologia que, num primeiro momento, seja neutra frente às alternativas positiva e negativa. Para conseguir isso, o grupo, independentemente de seu tamanho e tipo, inicialmente deveria ser compreendido como um mecanismo social fundado na necessidade ou no interesse psíquico do indivíduo, porque o auxilia na estabilidade e ampliação pessoais. Mas esta aspiração por uma retaguarda no grupo pode assumir formas distintas segundo o tipo de vínculo socializador ou das experiências sociais posteriores, que influenciam o grau da temática inconsciente no grupo. No que segue, tentarei desenvolver em linhas gerais este tipo de arcabouço categorial unificado, recorrendo ao conceito do reconhecimento. Num primeiro passo, será brevemente apresentada a premissa segundo a qual a dependência individual de experiências de reconhecimento social explica por que o sujeito individualmente aspira a ser membro em diferentes modelos de agrupamentos sociais. A cada forma de reconhecimento de que o indivíduo depende no decorrer de seu desenvolvimento, corresponde analiticamente uma forma diferente de aspiração de membresia em grupo (1). Esta premissa inicial, contudo, ainda contém uma forte abstração, porque são desconsideradas as necessidades individuais de fusão que, geralmente, também se concre- 
tizam na vida em grupo. Por isso, num segundo passo, tentarei corrigir a imagem idealizada de grupo que fora anteriormente introduzida, ao tematizar, com apoio em Donald Winnicott, as tendências regressivas que frequentemente codeterminam a vivência no grupo (2). Mas também este passo ainda não é suficiente para ajustar plenamente o conceito de grupo à realidade social. Naturalmente, o comportamento no grupo também pode ser influenciado por projeções e fantasias inconscientes que levam a uma patologização dos processos comunicativos e trazem consigo efeitos destrutivos (3). Portanto, eu sigo a ideia de retirar gradativamente aquelas idealizações que estavam na base da premissa inicial de uma diluição harmônica do eu no nós do grupo.

I

Às reflexões que quero expor com relação às diferentes formas de criação de grupos, subjaz uma concepção sobre o desenvolvimento social e da personalidade humana vinculada à teoria do reconhecimento. Sintetizando o resultado de pesquisas fomentadas, de um lado, pela teoria da relação com os objetos e, de outro, pela psicologia social estadunidense em seguimento a Mead, eu parto da convicção de que a formação do eu do sujeito se realiza através da gradual internalização de um comportamento social reativo, que tem o caráter do reconhecimento intersubjetivo. Na medida em que relaciona gradualmente a postura afirmativa, motivadora e reafirmadora de seus parceiros de interação, com sua própria realização de experiências ainda não sistematizadas, a criança pequena aprende a formar um núcleo interno de personalidade que, em certa medida, consiste em camadas de uma autorrelação positiva (Honneth, 2003). Podemos diferenciar mais este processo de socialização, se distinguirmos analiticamente esta autorrelação em vários estágios, em cada um 
dos quais aumenta o grau da capacidade de autonomia. A diferença entre esses estágios se mede no fato de que, com o aumento do número de parceiros de interação, também se torna mais complexo e exigente o comportamento de reconhecimento, por cuja internalização, a criança em desenvolvimento toma consciência de suas capacidades e direitos. Com base nesta premissa, parece ser pacífico assumir, como ponto de partida, a existência de um estágio na autorrelação infantil, no qual se aprende a conceber as necessidades e desejos experimentados internamente como sendo uma parte da própria pessoa, passível de ser articulada. Com um conceito feliz, que Erik $\mathrm{H}$. Erikson tornou frutífero para a psicanálise, pode-se designar como autoconfiança este tipo de segurança elementar sobre o valor das próprias carências (Erikson, 1974, p. 62). Enquanto a formação desta autoconfiança se realiza através da internalização bem sucedida do comportamento cuidadoso estável da pessoa de referência primária, como via de regra o pai ou a mãe assumem, a realização do segundo estágio já exige a ampliação da rede de parceiros significativos de interação: a criança precisa aprender a desenvolver uma autorrelação positiva adicional, para além da auto-confiança, que consiste na consciência elementar de ser considerada aos olhos dos outros como um ser responsável. Recorrendo às observações, que devemos tanto a George Mead como também a Jean Piaget, é possível supor que esse estágio se realiza através da internalização do comportamento lúdico praticado com outras crianças. A criança desenvolve primeiras, germinais formas de dignidade ou de autorrespeito, na medida em que ela se experimenta nas brincadeiras como um parceiro de interações, cuja capacidade de fazer julgamentos é percebida como importante ou confiável (Mead, 1973, p. 248). Claro que esse processo também é influenciado pela experiência de ser crescentemente respeitado pelos outros membros da família como um sujeito cujas convicções não são mais totalmente irrelevantes na tomada 
conjunta de decisões. Por fim, o terceiro estágio, com o qual se dá um novo passo na formação da autonomia, de modo algum se realiza somente depois de concluído o segundo, mas, por certo, em paralelo cronologicamente com ele, porquanto as experiências intersubjetivas que a criança necessita fazer, para no final alcançar consciência da importância de suas habilidades físicas e intelectuais próprias, geralmente são realizadas já no período em que ela adquire as primeiras formas de autorrespeito, através da interação com um outro fracamente generalizado (Mack e Ablon, 1983). Aliás, toda essa distinção em três estágios da autorrelação positiva - a autoconfiança, o autorrespeito e a autoestima - não deveria ser compreendida no sentido forte de uma sequência ontogenética. Antes, temos boas razões para admitir que as três formas de autorrelação podem se desenvolver, de forma ainda indiferenciada, já na internalização do comportamento cuidadoso dos pais, e só ser experimentadas posteriormente, no processo de gradativa diferenciação dos parceiros de interação, como aspectos específicos da própria vivência.

O quadro que resulta dessas reflexões sobre o processo de socialização (Sozialization) humana contém a ideia de um entrelaçamento entre individualização e socialização (Vergesellschaftung) que já permite tirar algumas conclusões sobre a importância dos grupos sociais para o amadurecimento individual. Eu havia afirmado que a internalização da relação de reconhecimento, que gradativamente se diferencia, leva ao surgimento de uma forma complexa de autorrelação, através da qual a criança aprende pouco a pouco a conceber-se como um membro competente de seu ambiente social. De certa forma, o devir da autonomização está entrelaçado com o processo de socialização, pois somente pode cumprir com as normas e habilidades socialmente esperadas aquele sujeito que as assumiu para si como o núcleo prático de sua própria autocompreensão. Mas, para manter vigentes e até mesmo expandir estas formas de autorre- 
lação prática positiva, o sujeito necessita participar de grupos sociais que, de certa forma, representam um espelho do comportamento original de reconhecimento. A experiência de ser considerado importante nas próprias carências, na sua capacidade de julgamento e, sobretudo, nas suas habilidades precisa ser renovada e reconstruída pelo sujeito sempre de novo na vida em grupo, para que ela não perca sua força e vivacidade na anonimidade do outro generalizado. De certa forma, o grupo permite ao adulto que ele siga experimentando aquela postura de reconhecimento direta, ainda mediatizada por gestos e palavras, que em circunstâncias favoráveis ele podia observar durante sua infância nas reações afirmativas das suas pessoas concretas de referência (Flanagan, 1991, parte 2). Nesse sentido, parece-me justificado admitir uma necessidade normal, quase natural dos sujeitos, de serem reconhecidos como membros em grupos sociais nos quais eles possam ver confirmadas duradouramente, através de interações diretas, suas necessidades, sua capacidade de julgamento e suas diversas habilidades.

Naturalmente, é possível diferenciar esses grupos, num primeiro momento, segundo as distintas formas de autorrelações positivas que neles experimentam uma espécie de reconhecimento reconcretizado. Para poder manter e, eventualmente, fortalecer sua autoconfiança, o sujeito necessita a experiência protetora da dedicação duradoura e confiável, tal como pode ser substancialmente possibilitada através de amizades e de relações afetivas. Nesse caso, não se pode falar propriamente de grupos, uma vez que a intersubjetividade almejada tem, antes, a forma de uma díade que parece ser moldada no equilíbrio entre fusão e separação segundo a estrutura da simbiose inicial. De qualquer modo, possivelmente não seja muito arriscado atribuir também ao adulto o impulso de procurar alcançar nestas formas íntimas, por vezes com conotação sexual, do estar a dois novamente uma consciência do valor de sua própria carência. Já 
que o amor, uma vez experimentado, não é suficiente para sustentar a autoconfiança conquistada durante o transcurso de toda uma vida, via de regra os sujeitos dependem da repetição de experiências de reconhecimento análogas à simbiose (Honneth, 1992, cap. 5). A situação é diferente naquele tipo de autorrelação positiva que denominei "dignidade" ou "autorrespeito". Normalmente, o sujeito aprende já com o fim da adolescência a separar a confiança no valor de seu próprio discernimento da confirmação concreta que ele havia recebido anteriormente no grupo dos seus pares. Talvez até a gradativa prática no papel de cidadão ou cidadã baste para dar durabilidade psicológica a este tipo de sentimento de autorrespeito, a ponto de, no futuro, ele se tornar independente de apoio e reafirmação direta. Mas um resultado tão bem sucedido só será possível em casos muito raros, pois, geralmente, a experiência dos deveres e, sobretudo, dos direitos de cidadania face à realização da vida permanece muito abstrata para fornecer suficiente autorrespeito. Por isso, os sujeitos, em especial ali onde o status de sujeito de direito lhes é negado na consciência pública, frequentemente dependem da participação em grupos sociais os quais Ihes asseguram uma espécie de respeito compensatório. Segundo uma expressão cunhada por Richard Sennet, estes grupos formam contraculturas do respeito (Sennett e Cobb, 1972, p. 79-89; cf. exemplo em Bourgois, 1995) nas quais prevalecem códigos obstinados de responsabilidade e estima. Assim, o número de seus membros raramente ultrapassa aquele tamanho que ainda permite interações diretas e controláveis, porque elas, no reflexo dos gestos e expressões animadores, precisam ajudar o indivíduo a adquirir uma consciência do valor de sua própria competência para fazer julgamentos. Mas lá onde esta abrangência do pequeno grupo for ultrapassada e, consequentemente, as interações face a face não forem mais possíveis, estaremos na presença de movimentos sociais, nos quais 
as normas alternativas de respeito se tornaram um meio generalizado. No lugar dos gestos concretos de reconhecimento, nesses grandes grupos anônimos, estabeleceram-se símbolos e rituais coletivamente compartilhados que, no entanto, têm força simbiótica suficiente para prover aos seus membros, mesmo à distância, o respeito compensatório.

Mas, sem dúvida, o solo mais fértil para a formação de grupos é dado por aquela camada da formação de personalidade que eu anteriormente denominei como autoestima, pois a consciência de que as habilidades próprias são importantes aos olhos dos outros certamente necessita, sempre de novo, uma reconfirmação ao longo da vida, para não se tornar muito fraca e impotente. É bem verdade que a base psíquica para este tipo de autorrelação positiva seja colocada já muito cedo nos casos de uma socialização bem sucedida, porquanto os pais, irmãos ou amigos coetâneos normalmente sinalizam claramente à criança que ela dispõe de um punhado de talentos e habilidades importantes. Mas, com o ingresso na escola e, sobretudo, mais tarde na vida profissional, cresce muito o círculo daqueles de cuja estima a própria autoestima depende, de modo que, em reação à maior vulnerabilidade, também aumenta o desejo de aprovação e confirmação concretas. Na necessidade de encontrar uma estima passível de ser experimentada diretamente no círculo das pessoas afins, está hoje um, senão o motivo central para a formação de grupos. Com a pluralização dos valores e o surgimento dos mais diferentes ambientes sociais, provavelmente essa tendência inclusive aumentou, porquanto praticamente não existem mais padrões de avaliação válidos para toda a sociedade, que pudessem informar, de certo modo anonimamente, o indivíduo sobre a importância de suas próprias realizações. Por consequência, hoje é praticamente incalculável o número de grupos organizados ou informais, cuja existência está dedicada exclusivamente à prática de determinados aspectos valorativos, e os quais permitem que 
seus membros se reafirmem reciprocamente em suas habilidades e talentos próprios. E a concorrência que normalmente é praticada dentro e mesmo entre esses grupos só é a expressão do fato de que este tipo de estima pressupõe a localização numa ordem classificatória.

A breve descrição panorâmica que fiz até aqui, da relação entre a necessidade de reconhecimento e a formação de grupos, pode dar a impressão de que todos esses grupos estariam livres de dinâmicas inconscientes. O objetivo da vida em grupo parece tão transparente a todos os membros, os motivos parecem estar tão claramente a serviço da saúde psíquica, que quase não é possível falar da influência de forças e sugestões inconscientes. Esta primeira apresentação, no entanto, é apenas o resultado de uma ficção metodológica devida à pretensão de revelar, primeiro isoladamente, os impulsos totalmente inocentes e, ao mesmo tempo, naturais para a formação de grupos. O panorama muda em um aspecto decisivo, tão logo no desejo de reconhecimento seja tematizada uma camada profunda que está além do controle do sujeito. Pois, com a separação da simbiose inicial, que se constitui no primeiro passo do reconhecimento da independência do outro, segundo Winnicott, a criança é, até certo ponto, sobrecarregada. Por isso, ela preserva, até a idade adulta avançada, o impulso de esporadicamente recair no estado da fusão no qual ela pode se sentir como ainda inseparada do outro sujeito. Quero mostrar, no segundo passo dessa exposição, que toda a vida em grupo é, em certo modo, perpassada por esta tendência. Mas o fato de talvez se tratar de impulsos inconscientes ainda não permite falar, aqui, de uma regressão no sentido patológico.

II

A razão que Winnicott dá para sua premissa central, no fundo, é fácil de compreender, mesmo que ultimamente tenha sido apresentada 
uma série de reservas com relação a ela. Em sua argumentação, o teórico da relação com os objetos tão somente tira as consequências da tese de que, no início da vida humana, precisamos contar com uma fase em que é vivenciada uma unidade simbiótica. Se for verdade que a criança pequena somente aprende a organizar suas forças psíquicas com a ajuda da internalização do modelo inicial de interação do cuidado de parte da mãe (ou de outra pessoa de referência), então parece que o estágio de vivência da unidade é precedido de uma ausência de diferenciação entre sujeito e realidade, no qual não se pode ainda falar de um outro experimentado como independente. Esta fase, bem inicial, para a qual, na psicanálise, há um conjunto de conceitos mais ou menos felizes, que vão de "narcisismo primário" até "simbiose", pode ser compreendida como sendo um período em que o bebê ainda vê seus próprios impulsos e pulsões tão fundidos com as reações de satisfação correspondentes de parte da pessoa de referência, que, em sua vivência afetiva, não pode existir uma separação entre o seu eu e a realidade (Winnicott, 1984). Portanto, a criança recémnascida não é dependente do cuidado e da assistência de sua pessoa de referência apenas no sentido prático da simples sobrevivência devido a sua situação de carências físicas; também no sentido mais profundo da realização de suas vivências, ela, de modo algum, está separada do ambiente de um comportamento reativo satisfatório que a envolve. Winnicott está tão convencido da importância cabal desta experiência simbiótica original - não apenas para a criança pequena, mas, em princípio, também ainda para a pessoa adulta -, que ele dedica sua teoria psicanalítica essencialmente à explicação daqueles mecanismos com a ajuda dos quais a gradativa percepção de uma realidade independente pode ser efetivada nos primeiros anos de vida. Mas, também aqui, é necessário enfatizar quase imediatamente que, para ele, não se tratava do processo de criação de um esquema cognitivo relativo à realidade objetiva e desprendida, 
mas tão somente dos mecanismos com os quais a criança consegue reconhecer a realidade de uma pessoa de referência independente de suas próprias fantasias de desejo. A hipótese com a qual Winnicott pretende explicar este passo decisivo no aprendizado da criança pequena consiste na grandiosa ideia dos objetos transicionais, dos quais aqui só posso apresentar um brevíssimo resumo (Winnicott, 1989, p. 10): na relação afetivamente investida com objetos de seu ambiente vivencial, sejam eles partes de brinquedos, a ponta do travesseiro ou o próprio polegar, a criança constitui para si uma esfera autônoma de realidade, normalmente com a tácita aceitação da pessoa de referência, que não pertence nem apenas à vivência interna, nem já ao mundo dos fatos objetivos. Ao contrário, o que justamente caracteriza este tipo de zona "intermediária" de vivência é que ela é vista por todos os participantes como uma esfera ontológica, com relação à qual a pergunta pela realidade sequer se coloca.

Se for considerada, também, a fase de desenvolvimento na qual ocorre a descoberta de tais objetos transicionais intermediários, então é inicialmente possível presumir que eles são criações substitutivas para a mãe perdida para a realidade externa. Porque eles têm uma natureza híbrida, a criança pode utilizá-los, diante dos olhos dos pais, praticamente para deixar suas fantasias simbióticas originais sobreviverem para além da experiência da separação e, ao mesmo tempo, testá-los criativamente na realidade. Contudo, nessa utilização lúdico-experimental, também se evidencia que a função dos objetos transicionais não pode ser limitada unicamente a assumir simbioticamente o papel da mãe experimentada no estado de fusão; pois a criança não se refere apenas com simbólica afetividade aos objetos por ela escolhidos, mas também os expõe reiteradamente a raivosos ataques e tentativas de destruição. Disso, Winnicott acredita poder deduzir que os objetos transicionais devam ser, de certo modo, elos ontológicos mediadores entre a experiência original do estar 
fundido e a experiência de estar separado: no trato lúdico dos objetos afetivamente investidos, a criança constantemente tenta superar simbolicamente o abismo dolorosamente vivenciado entre a realidade interna e externa. A circunstância de que a isso esteja vinculado, ao mesmo tempo, o início da formação de uma ilusão aceita intersubjetivamente permite a Winnicott, inclusive, dar um passo adiante e chegar a uma tese de grandes consequências: porque a formação dessa área ontológica intermediária se deve à solução de uma tarefa que permanece atual para o ser humano por toda sua vida, ela é o lugar psíquico de surgimento de todos aqueles interesses que o adulto associará com as objetivações culturais. Não sem alguma tendência para o exagero, Winnicott diz:

Presume-se, aqui, que a aceitação da realidade como tarefa nunca é completada, que nenhum ser humano está livre da tensão de relacionar a realidade interna e externa, e que o alívio dessa tensão é proporcionado por uma área intermediária da experiência que não é questionada (artes, religião etc.) [...]. Essa área está em continuidade direta com a área do brincar da criança pequena que se 'perde' no brincar (Winnicott, 1989, p. 23).

Assim, a ideia dos "objetos transicionais" leva à concepção de que o ser humano manterá por toda sua vida a tendência de se refugiar ocasionalmente atrás dos limites do eu já alcançados para poder suportar a crescente distância do estado original da simbiose. Surpreendentemente, Winnicott não inclui a vida intersubjetiva em grupos no rol das esferas da experiência que permitem tal regressão aliviadora. Contudo, haveria a possibilidade de interpretar determinados períodos de realização da vida em grupo segundo o mesmo esquema que ele descobre nas esferas culturais da arte e da religião. Também naqueles casos em que, durante a práxis em comum, as distâncias psíquicas entre os membros do grupo começam a desaparecer e cresce o sentimento da concordância afetiva, 
repentinamente parece desaparecer, para cada indivíduo, a pressão para aceitar a realidade externa como uma entidade independente. Todos conhecerão a experiência de só poder se separar de um grupo com um empurrão e mediante o emprego de muita energia, depois de se haver passado algumas horas ou dias num estado de comunhão intensiva. A difícil experiência de separação, no entanto, não se aplica aos membros individuais do grupo nem aos resultados produtivos da convivência, mas refere-se unicamente ao estranho estado de levitação, no qual as fronteiras antes erigidas frente aos outros houveram sido temporariamente derrubadas. Por conseguinte, a fascinante observação de Winnicott pode ser ampliada, no sentido de que, ao lado da arte e da religião, também a intersubjetividade do grupo forma uma esfera de experiência que faz desaparecerem as fronteiras entre a realidade interna e externa; sim, se levarmos a sério sua indicação a respeito da origem dessas zonas intermediárias na brincadeira infantil, então talvez seja possível, inclusive, dizer que a experiência da fusão no grupo representa, para o adulto, o espelhamento mais direto de suas experiências na tenra infância.

Dessa extensão do diagnóstico de Winnicott resulta a consequência de que a vida intersubjetiva no grupo em geral estará caracterizada por circunstâncias regularmente recorrentes e episódicas, que levam a fusões mais ou menos intensas entre os membros. Mesmo que o espectro dessas vivências coletivas de fusão seja extremamente amplo, todas elas seguem o mesmo percurso de uma gradativa ascensão, um repentino apogeu e um subsequente achatamento da aproximação entre os participantes: seja na forma subliminar da cooperação totalmente irrefletida e vivenciada extaticamente, seja na forma incomparavelmente mais ruidosa do ritmo da dança corporal na massa jubilante, seja no estádio de futebol, no concerto de rock ou no isolamento do grupo de trabalho absolto como que imerso num jogo, as circunstâncias da vida em grupo sempre se caracterizam por aquela 
tendência a uma fusão quase orgiástica que Durkheim denominou momentos de efervescência coletiva (Durkheim, 1981, p. 296; cf. Joas, 1997, cap. 4). Não se trata, obviamente, de uma temática inconsciente, relativa à qual no interior do grupo pudessem eclodir conflitos que estivessem relacionados às pulsões primitivas; antes, a fusão revivida esporadicamente alimenta o sentimento comum de compartilhar as normas de respeito e os valores à luz dos quais os sujeitos podem se reconhecer reciprocamente.

Se, portanto, anteriormente tínhamos dito que todo sujeito adulto costumeiramente terá o impulso de se vincular a grupos nos quais o valor da própria personalidade seja espelhado na forma de uma vivência, então podemos agora dar um passo adiante: porque os mesmos sujeitos que dependem da confirmação de sua estima no grupo, ao mesmo tempo, são impulsionados pela necessidade de deixar-se regredir para trás dos limites do eu já alcançados, a vida no grupo sempre estará perpassada por tendências de fusão. Obviamente, os impulsos regressivos que normalmente acompanham tais experiências de fusão não são um indicador de reprimitivizações patológicas, mas expressão da recuperação de vitalidade psíquica, pois todo grupo social, na medida em que cumpre a função de uma reconcretização do reconhecimento intersubjetivo, precisa, nas circunstâncias da comunidade desinibida, reforçar justamente aqueles valores e normas aos quais os sujeitos devem a confirmação de sua estima. Por isso, o equívoco da psicanálise tradicional consiste em igualar completamente estas manifestações "sadias" de regressão com aquelas nas quais energias primitivas são ativadas no interior de grupos de modo ameaçador para a identidade (Honneth, 2007). Claro que também existem tais patologias da vida em grupo, mas elas não devem ser identificadas com as fusões periódicas através das quais o grupo renova sua própria cultura de reconhecimento.

Com isso, chego ao terceiro e mais breve passo no meu texto. Também as reflexões até agora apresentadas são ainda, de certo modo, o 
resultado de uma abstração metodológica, pois eu, mesmo levando em consideração as tendências regressivas, tratei o grupo social como se ele sempre fosse livre de temáticas e conflitos que tivessem um caráter estranho e até patológico. É bem verdade que a maioria dos conflitos que tipicamente surgem no interior de grupos são, sobretudo, de tipos quase conscientes, fáceis de serem reconstruídos racionalmente. Em geral, eles estão relacionados à necessidade de interpretação e hierarquização das realizações individuais que os sujeitos devem poder demonstrar para contarem como membros reconhecidos. Do fato de que, no interior do grupo, surgem ordens hierárquicas disputadas resultam concorrências as quais, por sua vez, podem fomentar alianças parciais e fracionamentos. Afinal, desses fracionamentos possivelmente surjam dinâmicas psíquicas que podem fugir do controle a ponto de assumirem dimensões dolorosas e, até mesmo, ameaçadoras da identidade para alguns. Mas nós não nos referimos a esses conflitos quando falamos da patologia de um grupo, pois eles têm um núcleo racional, na medida em que resultam da circunstância da possibilidade de se hierarquizar as realizações individuais, o que pode levar a uma inundação da vida do grupo com posturas estratégicas, rancor e inveja. E, naturalmente, também a obrigação de libertar-se do estado de fusão do grupo, sempre de novo, pode levar alguns membros a reações defensivas e a tendências à negação, pois a tarefa da renovada aceitação da independência do outro nem sempre é fácil de realizar. No entanto, também essas dificuldades individuais de adaptação só causarão uma patologização de toda a vida do grupo, se não houver um número suficiente de membros que prestam uma ajuda totalmente discreta, praticamente terapêutica e normalizada. 
Nos escritos de Freud sobre a psicologia de massa, frequentemente é sugerido que a vida em grupo como tal seja responsável pelas regressões que motivam os membros à subjugação à figura do líder fantasiada como onipotente. Não seriam os defeitos psíquicos do indivíduo, mas a atmosfera sedutora do grupo anônimo o que faria desaparecer as capacidades individuais de controle, a ponto de que as projeções da primeira infância pudessem se tornar o impulso para agir socialmente (Freud, 1999). Também Adorno, por motivos que certamente estão relacionados com o fato de ter vivenciado as massas do nacional-socialismo, por muito tempo parece ter insistido nesse tipo de interpretação. Em seus textos sobre psicologia social, a concepção de que, na vida em grupo, os sujeitos têm pouco controle sobre suas energias psíquicas desempenha um papel decisivo (Adorno, 1972). Somente alguns anos após seu retorno do exílio, ele manifestamente mudou sua concepção, pois, nos "excursos sociológicos", que ele publicou junto com Horkheimer, no verbete "grupo" encontra-se uma frase que vem amplamente ao encontro da perspectiva defendida aqui: Para qualquer humanidade, a proximidade íntima de pessoas e, com isso, o pertencimento a grupos que permitam contato humano imediato, é um pressuposto óbvio (Institut für Sozialforschung, 1956, p. 64). Segundo esta afirmação, não pode ser o próprio ambiente psíquico do grupo o que leva ao surgimento de manifestações patológicas da disposição projetiva à obediência. Antes, ao contrário, devem ser distúrbios individuais de personalidade dentro de um grupo que devem ter constituído uma ligação tão infeliz, que as relações de interação como um todo são investidas de potenciais conflitivos não resolvidos, dos quais, então, todos membros participam regressivamente. Em oposição a Freud e a alguns de seus seguidores, os grupos não constituem "em geral", como afirma Kernberg (2000, p. 11), uma ameaça à identidade pessoal. Este tipo de desenvol- 
vimentos ameaçadores só ocorre, se as energias primitivas reativadas dos membros individuais confluírem para uma corrente que arrasta consigo as capacidades de controle de todos os outros. Entre os distúrbios individuais que podem desempenhar um papel dinâmico em tais situações, quero destacar dois que me parecem ser particularmente influentes.

Para a patologização de grupos, parece ser responsável, primeiro, o acúmulo de um tipo de personalidade que permaneceu estacionado no estágio das idealizações primitivas por não ter concluído os processos de separação. Indivíduos deste tipo, em possível associação com um comportamento reativo "ocnófilo", como descrito por Balint (1994, cap. 2), inclinam-se a uma vinculação medrosa a um objeto afetivo ao qual eles atribuíram habilidades onipotentes. Se o número de membros com esse perfil psíquico ultrapassa uma determinada proporção, para além da qual a influência civilizadora dos outros diminui ou se torna insignificante, então, por contágio ou transmissão, o grupo como um todo pode desenvolver um estilo de comportamento patológico. Os membros vivenciam a figura idealizada do líder como todo-poderoso e onisciente e a si próprios, ao contrário, como insatisfatórios, imaturos ou incompetentes. Se o dirigente não corresponder duradouramente ao ideal, então ocorre uma reação de negação ou anulação, seguida de perto pela procura por um líder substituto. Em seu estudo esclarecedor, Bion (2001, cap. 2) descreveu grupos deste tipo como "grupos dependentes". Eles, obviamente, de modo algum podem cumprir a função de assegurar aos seus membros uma cultura do reconhecimento compacta e vivenciável.

Uma segunda forma de patologização de grupos pode resultar do acúmulo de um tipo de personalidade que tem um potencial quase incontrolável de agressividade devido a experiências anteriores de desrespeito ou abandono (cf. Sutterlüty, 2002). Indivíduos deste tipo estarão inclinados a projetar suas fantasias destrutivas sobre o ambiente, de modo que se perce- 
bam constantemente como cercados e ameaçados por inimigos externos. Se essas fantasias se espalharem pelo resto do grupo, através de ressonâncias comunicativas e incitamento, sem que os membros mais maduros consigam contribuir para uma readaptação realista, então também este grupo rapidamente desenvolverá um estilo patológico coletivo. Pelo fato de que os membros não suportam uma contestação das ideologias desenvolvidas para sustentar suas fantasias paranoicas, eles desenvolverão uma tendência ao fracionamento em subgrupos. Um sentimento comum abrangente e de proximidade só pode ser restabelecido através da negação coletiva das hostilidades internas, o que reforça ainda mais a intensidade das agressões externas voltadas ao inimigo. Segundo Bion, desconfiança, luta e temor da destruição são os traços essenciais deste tipo de associação patológica, que ele tenta caracterizar com o conceito de grupos de luta-fuga (Bion, 2001, p. 52). Também estes grupos estão à maior distância imaginável daqueles grupos cuja existência se deve à necessidade dos indivíduos de experimentarem formas personalizadas de reconhecimento.

Com certeza, o espectro dessas possíveis distorções não está esgotado com estes dois modelos de patologização de grupos sociais. O próprio Bion lista, ainda, pelo menos um outro tipo fundamental que, segundo os critérios clínicos, ele considera perturbado (Bion, 2001, p. 89). Mas o sentido das reflexões que acabo de apresentar não era o de fazer um panorama tão completo quanto possível. Através da via indireta da demonstração dos desvios negativos, eu queria fundamentar, uma vez mais, a tese que estava no centro de minha exposição: o eu busca o nós da vida comum em grupo, porque, mesmo depois de amadurecido, ele ainda depende de formas de reconhecimento social que possuam o denso caráter da motivação direta e da confirmação. Ele não pode manter nem o autorrespeito nem a autoestima, sem a experiência de apoio que se faz através da prática de valores compartilhados no grupo. Por conseguinte, o grupo, 
longe de representar uma ameaça para a identidade pessoal, é, nas palavras de Adorno, uma fonte da humanidade. Aquelas patologizações que, sempre de novo, podemos observar na vida em grupos, por sua vez, são o resultado de uma infiltração por distúrbios individuais de personalidade. Por isso, a situação dos grupos numa sociedade sempre é tão boa ou tão ruim quanto o são as condições de socialização que nela prevalecem.

\section{Referências}

ADORNO, Theodor $\mathrm{W}$. Freudian theory and the pattern of fascist propaganda. In: ADORNO, Theodor W. Gesammelte Schriften. v. 8, Frankfurt am Main: Suhrkamp, 1972, p. 408-433 [Teoria freudiana e o padrão da propaganda fascista. Disponível em: http://antivalor.atspace.com/Frankfurt/adorno71.htm].

BALINT, Michael. Angstlust und Regression. Stuttgart: Klett-Cotta, 1994 [original: Thrills and Regressions, 1959].

BERKING, Helmuth. Masse und Geist: Studien zur Soziologie in der Weimar Republik. Berlin: Wissenschaftlicher Autoren-Verlag, 1984.

BION, Wilfred R. Erfahrungen in Gruppen und andere Schriften. $3^{a}$ ed. Stuttgart: Klett-Cotta, 2001 [Experiências com grupos. São Paulo e Rio de Janeiro: Edusp e Imago, 1975].

BOURGOIS, Philippe. In search of respect: selling crack in El Barrio. Carnbridge: Cambridge University Press, 1995.

CANETTI, Elias. Masse und Macht. Düsseldorf: Walter Verlag, 1960 [Massa e poder. São Paulo: Cia. das Letras, 2005].

COOLEY, Charles H. Social organization. New York: Scribner, 1963.

DURKHEIM, Emile. Die elementaren Formen des religiösen Lebens. Frankfurt am Main: Suhrkamp, 1981 [As formas elementares da vida religiosa. São Paulo: Martins Fontes].

ERIKSON, Erik H. Identität und Lebenszyklus. Frankfurt am Main: Suhrkamp, 1974 [O ciclo de vida completo. Porto Alegre: Artes Médicas, 1998].

FINK-EITEL, Hinrich. Gemeinschaft als Macht: zur Kritik des Kommunitarismus. In: BRUMLIK, Micha; BRUNKHORST, Hauke (orgs.). Gemeinschaft und Gerechtigkeit. Frankfurt am Main: Suhrkamp, 1993, p. 306-322. 
FLANAGAN, Owen. Varieties of moral personality: ethics and psychological realism. Cambridge: Harvard University Press, 1991.

FREUD, Sigmund. Massenpsychologie und Ich-Analyse. In: Freud, Sigmund. Gesammelte Werke. v. 13, Frankfurt am Main: Fischer, 1999, p. 71-162 [Em: Psicologia das massas e análise do eu e outros textos. Obras Completas, vol. 15. São Paulo: Cia. das Letras].

HONNETH, Axel. Objektbeziehungstheorie und postmoderne Identität: über das vermeintliche Verhalten der Psychoanalyse. In: HONNETH, Axel. Unsichtbarkeit: Stationen einer Theorie der Intersubjektivität. Frankfurt am Main: Suhrkamp, 2003, p. 138-161.

HONNETH, Axel. Kampf um Anerkennung: zur moralischm Grammatik sozialer Konflikte. Frankfurt am Main: Suhrkamp, 1992 [Luta por reconhecimento. São Paulo: Editora 34, 2003].

HONNETH, Axel. Angst und Politik: Stärken und Schwächen der Pathologiediagnose von Franz Neumann. In: HONNETH, Axel. Pathologien der Vernunft: Geschichte und Gegenwart der Kritischen Theorie. Frankfurt am Main: Suhrkamp, 2007.

INSTITUT FÜR SOZIALFORSCHUNG (org.). Soziologische Exkurse: nach Vorträgen und Diskusionen. Frankfurt am Main: Fischer, 1956.

KERNBERG, Otto F. Ideologie, Konflikt und Führung: Psychoanalyse von Gruppenprozessen und Persönlichkeitsstruktur. Stuttgart: Klett-Cotta, 2000 [Ideologia, conflito e liderança em grupos e organizações. Porto Alegre: Artmed, 2000].

KLUTH, Heinz. Die Halbstarken: Legende oder Wirklichkeit. Deutsche Jugend. v. 4, Nov. 1956, p. 495-503.

JOAS, Hans. Die Entstehung der Werte. Frankfurt am Main: Suhrkamp, 1997.

MACK, John E.; Ablon, Steven L. (orgs.). The development and sustenance of self-esteem in childhood. New York: International Universities Press, 1983.

MEAD, George H. Geist, Identität und Gesellschaft. Frankfurt am Main: Suhrkamp, 1973.

PIAGET, Jean. Das moralische Urteil beim Kind. Frankfurt am Main: Suhrkamp, 1976 [O juízo moral na criança. São Paulo: Summus, 1994].

SANDEL, Michael. Liberalism and the limits of justice. Cambridge: Cambridge University Press, 1982.

SENNETT, Richard; COBB, Jonathan. The hidden injuries of class. Cambridge: Cambridge University Press, 1972. 
SUTTERLÜTY, Ferdinand. Gewaltkarrieren: Jugendliche im Kreislauf von Gewalt und Missachtung. Frankfurt am Main: Campus Verlag, 2002.

TRASHER, Frederic M. The gang: a study of 1313 gangs in Chicago. Chicago: University of Chicago Press, 1917.

WINNICOTT, Donald. Reifungsprozess und fördende Umwelt. Frankfurt am Main: Fischer, 1984 [O ambiente e os processos de maturação. Porto Alegre: Artmed, 1983].

WINNICOTT, Donald. Übergangsobjekte und Übergangsphänome. In: WINNICOTT, Donald. Vom Spiel zur Kreativität. Stuttgart: Klett-Cotta, 1989 [Objetos transicionais e fenômenos transicionais. In: O brincar e a realidade. Rio de Janeiro: Imago, 1975, p. 13-44].

Recebido em: 14/03/2013

Aceite final: 30/06/2013 